\title{
Analysis of the Operation of Maternity-Baby-Children E-commerce Platforms - A Case Study of Haiziwang APP
}

\author{
Zhijie Xia \\ E-commerce, School of Economy and Trade, Zhejiang Industry \& Trade Vocational College, \\ Wenzhou, Zhejiang 325003
}

Keywords: Maternity-baby-children; Online mall; Haiziwang; Problem analysis

\begin{abstract}
With the continuous rapid development of Chinese economy over these years, people's living standard and quality are improving. A gradual increase in labor income has led to the drastic change in the concept of consumption, which has also stimulated the diverse changes of consumer needs. In such an economic situation, how to meet the diversified consumer needs of members to a large extent has become a shared concern among enterprises, and the solution to this problem will also open a new door to our economic development. The nationwide implementation of "Two-child Policy" promotes the development of maternity-baby-children development, how to improve the market share in this context of changing economic situation becomes a more critical concern. This thesis mainly reveals the APP development of Haiziwang Kid Products (China), its major problems and the workable measures for these problems.
\end{abstract}

\section{Introduction}

As of April 2016, the cumulative number of China's mobile applications has reached 6.71 million, while that of third-party APP stores has hit 5 million. The key part of business APP marketing is to make consumers further understand its brand or products and establish an emotional connection between its brand and consumers through full display of products ${ }^{[1]}$. The brand APP can be used to deliver the brand concept, deepen the brand image, establish the brand review, contribute to enhancing the brand and product recognition, and bridge between the brand and consumers.

According to the data of 2015 released by Roland Berger, the trade volume of Maternity-Baby-Children e-commerce has reached RMB 360.6 billion, with a YoY increase of $98.3 \%$, and it has maintained a growth rate of more than $50 \%$ over these years. In particular, the overall market scale of Maternity-Baby-Children has reached RMB 1.9 trillion by the end of 2015, if the growth rate keeps incremental, it will hit RMB 2 trillion by the end of this year ${ }^{[2]}$.

\section{APP Marketing of Haiziwang}

Company Profile. "Haiziwang", also referred to Haiziwang Kid Products Co., Ltd, is a company headquartered in Nanjing, Jiangsu. Haiziwang is engaged in providing one-stop growth services for children aged 0-14 and expectant mothers. It always strives to become the preferred service provider for the lifestyle of Chinese new families by exploiting the membership relationship, building the concept of the customer relation-based operation of membership assets, and vigorously developing the Omni-Channel strategy [3]. 


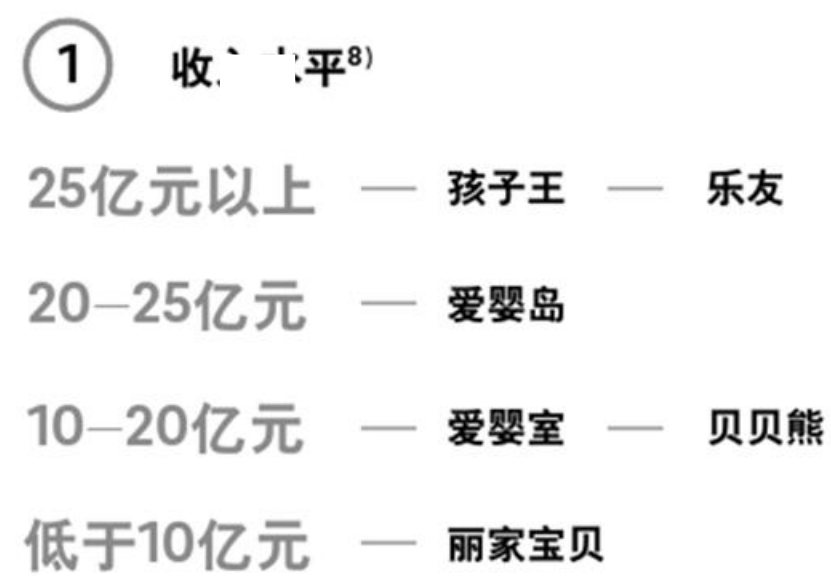

Figure 1. Analysis of the Operation Maternity-Baby-Children E-commerce Platform - A Case Study of Haiziwang APP

Present Marketing Status of Haiziwang APP. In the context of "Internet +", Haiziwang maintains as the industrial leader at an amazing growth rate, and becomes one of the largest Maternity-Baby-Children retailing businesses in respect of the online-offline integration and the scale of dual expansion.

As a giant in Maternity-Baby-Children retailer chain, haiziwang.com began its official operation earlier in November 2009, maintained the original traditional channels and actively exploited the online channels. In addition, it engages in the development of mobile APP while opening its online mall. Earlier in 2014, Haiziwang APP was officially launched ${ }^{[4]}$.

As a Maternity-Baby-Children O2O platform, Haiziwang APP was in TOP 3 of the domestic e-commerce platforms for three months in a row (May, June, July), while sustaining its offline development. Haiziwang APP elbowed into TOP 3 of the domestic competitors within one year from its official launching ${ }^{[5]}$.

Potentials of APP. The figure below indicates the great potentials for China's Maternity-Baby-Children market, which will keep growing in the next few years, and there is an enormous prospect for online development.

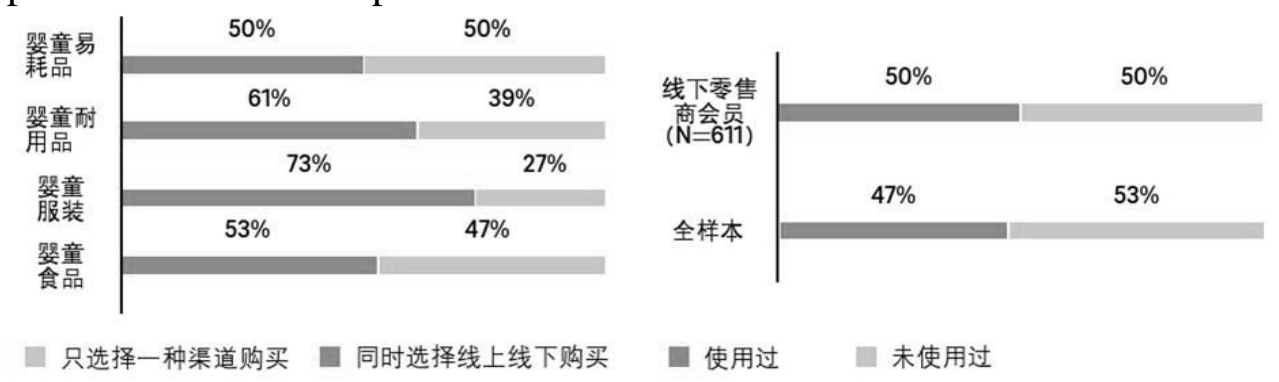

Figure 2. Ratio of the online sales to the offline sales in Maternity-Baby-Children industry

The rapid development of Haiziwang APP and its presence as a leader in the domestic Maternity-Baby-Children market industry can be attributed to the general integration of its online and offline membership system, more foreign quality commodities listed under "Global Purchase" in Haiziwang APP, and the fulfillment of high-quality living needs of its membership families. In addition, children's insurance and other virtual products available on the online mall in Haiziwang APP are a good complement to the commodity categories of brick-and-mortar stores, which also improves its commodity services. With a view to the childcare growth services, Haiziwang has launched its childcare advice service in APP, and appoints childcare specialists to respond to the related issues from members in real time. In this way, the online and offline integration and 
connection can be achieved to give a package of solutions to the childcare issues arising from the growth of their kids. And more professional and quality services are provided for each family. However, a lot of issues are also exposed during the rapid development of Haiziwang.

\section{Issues about Online Mall Marketing}

Weak Integration of the Industrial Chains. Most of the delivery services are outsourced to the third-party logistical providers, the own logistical distribution system is only available in limited areas, but with the increase of economic levels, the business scale of those logistical providers is generally small, the service personnel has a limited competence, which means that such a logistical distribution system fails to meet the needs anymore. The consumer experience of a member involves the process from purchasing at Haiziwang APP, submitting an order, to the delivery of goods through logistical distribution. Every process is related to their impressions on Haiziwang. Whenever the expectation of a member cannot be met, his dissatisfaction with Haiziwang product or service will travel around quickly.

Underperformance of the APP Online Experience. There is a weak online-offline connection of Haiziwang APP. Its online operation is in the fast-track development, a large number of members will flow on a daily basis. In July 2016, the number of active members was 959000, despite the increase of order fulfillment rate, it may cause a huge load on the follow-up processing of orders, and all commodities available in "Global Purchase" are shipped from the bonded areas. However, the data shows that about 15 days are required to fulfill an order from ordering till delivery, which not only interferes with the purchase experience of members, but also incurs a negative review [6].

Online Transaction Security of Haiziwang APP. According to a questionnaire survey, $31 \%$ of Haiziwang APP users reported that the biggest challenge for online transaction is security, while $30.1 \%$ reported that the product quality, after-sales service and credit standing of manufacturers are insecure, which means that $61.2 \%$ or two thirds of the respondents believe that the security cannot be guaranteed. This is a huge obstacle against the popularity and promotion of Haiziwang APP, so $42.8 \%$ of its users choose the payment term of cash on delivery, especially for a single product at a price of more than RMB 1,000, 73.3\% prefer such payment term [7]. If the security concern cannot be eliminated, it would be difficult to break the obstacle to its APP promotion.

\section{Countermeasures for Online Marketing Application}

Strengthen the integration of industrial chains. In the context of big data, it is very important to add control on the supply information, only by the data analysis could we precisely grip the market trend and development, and forecast the sales volume in the next cycle[8].How to ensure the quality of Maternity-Baby-Children products provided by the upstream suppliers and the quality of services provided by the downstream third-party logistical providers? The most effective way is to intensify the regulation on each process and establish a good appraisal system. And partner with the businesses for their own benefits of development, until their own brands are established successfully [9].

Enhance the Online Customer Satisfaction. 1. Publicize the online sales data, which allows customers to make an intuitive judgment, and a large volume of sales data will properly enhance the customer recognition, while promoting the customer purchase behavior.

2. In addition to the addition of more features, APP should also provide more comprehensive services and improve the integrity and preciseness of service contents based on the customer orientation.

3. Enhance the storage capacity of backstage data and prevent the collapse of APP or other events by increasing the backstage hosts.

Improve the after-sales and Quality Guarantee. 1. Strengthen the staff training. Improve the technical competence, good work ethics and service skills of customer service personnel. Ensure that the staff thinks about which kind of services members may need by putting themselves in the 
shoes of members and from the standpoint of members, we will enrich the service contents depending on their needs and keep increasing the service items for the same purpose [10].

2. Improve the quality guarantee for products. Manager should make clear the due responsibilities for each employee, strictly implement the quality liability regulations, grant rewards or impose punishment depending on their working performance, and only in this way could the staff quality awareness be enhanced. In addition, properly take care of and deal with the complaints made from members.

\section{Summary}

The development of business APP follows the trend of this age. It is an age of internet, the online marketing has become a trend, subject to the current social status, the mobile e-commerce has been the mainstream, a good APP project will deliver greater benefits to the company. Mobile e-commerce provides customers with service information, avoids extra investment and cost expenses, ensures greater flexibility, and allows for more convenience of the business operation.

The enhanced recognition of Haiziwang has led to a growing number of APP users, the experience and feedback of members should be noted during its development, if the issues that hinder the APP development could be solved, Haiziwang will be elevated to a higher level.

\section{References}

[1] Jiang Yuanfang. "Exploration and Practice of the E-commerce Models of Direct Retailing Chain" [J]. lunwencloud.com: 2013(1):113-115

[2] "From Online to Offline, Another O2O Path for Traditional Brands" (J/OL). Luwencloud.com: 2015, 66-69.

[3] Wang Juan. "A Brief Analysis of the Business Model of Shanxi TS Supermarket Group in the Context of E-commerce" [J]. China Economist: 2015, 76-79.

[4] Feng Yingjian. Network Marketing Fundamentals and Practices [M]. Beijing: Tsinghua University Press, 2004

[5] Jiang Yao. "C2B Model - The Inevitable Trend of E-commerce Future Development" [J]. Business Analysis: 2014, (19)

[6] Lei Guangfu. E-commerce Studies [M]. Economic Science Press: 2003, 45-47.

[7] Bu Sen. "Market Expansion of Rural Chain Businesses and Its Path Analysis" [J] Seeker: 2012, 68-70.

[8] Zhang Rongqi, \& Tian Wenli. “O2O Business Model of Catering Chain Businesses” [J]. China Market: 2014, 57-60.

[9] Industrial Economics - Li Xiao, Xia Shanshan, \& Wang Mingyu. "Development Status of China Maternity-Baby-Children E-commerce and Its Prospect Analysis" [J]. China Journal of Commerce: 2015, 150-152.

[10]Market Research - Wang Wanzhu, \& Jin Ye. "Current Market Status of China Maternity-Baby-Children Products and Its Future Trend” [J]. China Business \& Trade: 2011, 20-21. 